\title{
Questions of trust (and distrust)
}

\author{
Andrew Flinn • Elizabeth Shepherd
}

Published online: 15 November 2011

(C) Springer Science+Business Media B.V. 2011

On 5th and 6th July 2010, Wolfson College in Oxford (UK) played host to an international conference of archival educators, researchers, practitioners and other interested individuals to debate the topic "Questions of trust? Archives, records and identities." This special issue of Archival Science presents thirteen articles originally delivered in Oxford that summer. The conference was organised by the UK and Ireland Forum for Archives and Records Management Education and Research (FARMER) and the Network of Archival Educators and Trainers (North West Europe) (NAET) and supported by the International Council on Archives' Section on Archival Education and Training (ICA-SAE), sponsor of the keynote address given by Anne Gilliland.

FARMER brings together archives and records management educators and researchers from seven universities in the UK and Ireland (namely University College London, University College Dublin, and the Universities of Liverpool, Aberystwyth, Northumbria, Glasgow and Dundee) to discuss and collaborate around matters of mutual interest. The Wolfson conference was the second international event to be organised by FARMER, following the "Developing the 21st Century Professional: a learning continuum for archivists and records managers" conference held in Aberystwyth in 2006. Building on the success of that first venture, the Wolfson conference attracted approximately 70 delegates from over a dozen countries. The conference was immediately preceded by the fifth International Conference on the History of Records and Archives (I-CHORA 5) in London and followed by a meeting of the ICA-SAE steering committee with the result that for 1 week in the summer of 2010, the UK played host to a series of intense and stimulating discussions about many of the current challenges and trends in archival education and research.

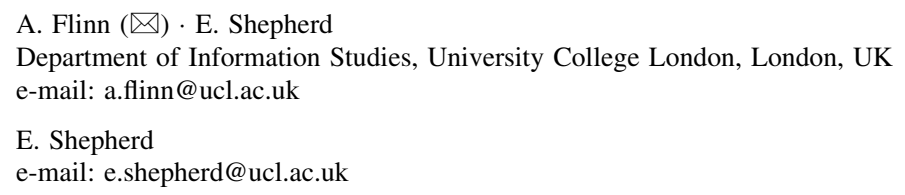


As conference organisers, we successfully aimed to gather together as wide a range of (English-speaking) international scholars from within our discipline as possible. Over the last few years, the I-CHORA conferences, the Investigating the Archive and the Memory and Identity Research events organised by the University of Dundee and the North American Archival Education and Research Institutes (AERI) have all helped to stimulate and sustain an international dialogue between archival scholars and educators, and the FARMER conference was part of this continuing and evolving conversation. However, it was also the intention of the conference organisers to stimulate more inter-disciplinary discussions with colleagues from other fields such as anthropology, museology, informatics and philosophy, and this was less successful. At present it seems that as archival educators and researchers we have been successful in establishing and growing an international network; however, we are still largely talking to ourselves, and future FARMER conferences and similar events must seek to extend the dialogue further afield discipline-wise.

The theme of the conference was intentionally a broad one-exploring the relationship of archives and records (and archivists and records professionals) to notions of trust and identity, particularly in the information-rich and increasingly disintermediated digital world most of us inhabit. The digital environment has suggested many new questions and concerns for those interested in archives and records as well as reformulating some traditional ones. Chief amongst these questions are those which relate to trust (in records, in organisations and in systems) and to identities and the extent to which archives and records support the construction, articulation and demonstration of those identities.

Recent years have witnessed a growing recognition of the political nature of archives and records, and of archives and records management. The conference sought to place questions of trust and identity at the heart of these political concerns and processes. Amongst the themes, contributors were asked to consider were the following: Can records and archives be trusted and what might "trust" mean in this context? Can professional practice and systems ensure the "trustworthiness" of archives and records? Does public access to archives and records ultimately support or undermine trust in governments, public servants and commercial organisations? How might archives and records support the construction and articulation of individual and collective identities and what role is played in such constructions by the question of "trust" in these records and in the authority of those who manage such materials?

As Michael Moss, one of the keynote speakers, has suggested, the philosopher Onora O’Neill's 2002 British Broadcasting Corporation Reith lectures on “Questions of Trust," remain an extremely valuable examination of some of the issues facing information and records professionals. O'Neill makes the case for clarity of thought and expression and admonishes us not to confuse declining deference, a media-fostered climate of suspicion or even a more critical and enquiring approach to those in positions of authority with a full-blown crisis or absolute disappearance of trust. Trust remains an indispensable commodity critical to the effective functioning of modern societies.

However, even whilst we accept O'Neill's advice to be more precise in how we diagnose the state of public trust and distrust, the underlying concerns about the 
information we are given and those who are responsible for the creation and dissemination of that information have been intensified by developments since 2001 . O'Neill's lectures were delivered in the immediate post-9/11 period, less than a year into the "war against terror." Since then the public has witnessed (amongst other things), the decision to go to war in Iraq and the "falsification" of evidence to justify that action; the detention, rendition and alleged torture of terror suspects without trial and due process; revelations inspired by the extension of Freedom of Information legislation in the UK and elsewhere resulting in scandals over the behaviour of public servants and elected officials; allegations about widespread, even endemic malpractice in the media accompanied by ever-expanding sources of "alternative" and "authentic" yet unverifiable citizen opinions available at the click of a mouse; the continual and growing release of unmediated information made available via Wikileaks and similar unofficial channels; the growth of online "astroturfing" whereby political parties and large corporations attempt to discredit opponents and lead public opinion by faking grassroots campaigns and distributing propaganda as objective and respectable (yet ultimately unattributable) scientific evidence; and last but not least the serial corruptions, deceits and "dodgy dealings" in the banking and finance sectors that led to the near collapse of the financial system, global recession and almost universal austerity programmes. At the heart of each of these "scandals" is information (being falsified, withheld or unverifiable), its communication to the public and the probity of those in positions of authority. O'Neill may be correct to advise against diagnosing a complete breakdown of trust throughout society; however, the developments of recent years have surely contributed to a growing sense of public distrust and mistrust of authority and official sources of information with consequences for all involved in the management of records and information.

Taken with a decline in popular uncritical deference towards the professions and authority generally, this atmosphere of distrust makes it ever more crucial that recordkeepers can demonstrate why they and the records they keep deserve to be trusted. It is no longer sufficient to demand trust on the basis of some abstract claim to professional authority, and that trust must be earned and deserved through observable practice, effective performance and ethical behaviour.

The conference benefited hugely by having three highly respected keynote speakers able to address different aspects of these developments and the implications for recordkeeping and recordkeepers in a stimulating and thought-provoking manner. First, Heather MacNeil reflects on the historical development of archival professional identity whereby the twin pillars of the archivist as "trusted custodian" and archival institutions as "trusted repositories" combine to ensure "trustworthy records." Whilst acknowledging the continued strength and resonance of such traditions, MacNeil illustrates how recent technological and philosophical developments should inspire archivists to explore other ways of conceiving of their professional identities and core duties. Anne Gilliland's keynote and article here also engage with professional ethics and traditional exhortations to observe "archival neutrality" in order to guarantee trust and belief in professional impartiality. Gilliland outlines some challenges to these traditional assumptions and in their stead makes the case that public trust in the profession and in professional practice may be best engendered by an open acknowledgement of the agency of archivists and records professionals and by a 
more active engagement with the social justice elements of their work. Michael Moss' address closed the conference and concludes this volume by exploring the meaning of terms such as trust, accountability, transparency, audit and governance and suggests that they are frequently employed in a misleading or simplistic way when deployed in arguments to support the recordkeeping mission. Moss concludes that there is a wealth of thinking on these issues from other disciplines that archivists and information professionals must engage with more fully, particularly on how the use and management of information coincides with these concepts in a digital age.

Price and Smith's article advances the notion of a "trust continuum" in the context of the abundant flow of digital information, using examples from Library and Archives Canada to demonstrate how trust or distrust is realised in complex social relationships and inter-relationships between creators, recordkeepers and the users. Oliver, Chawner and Liu also focus on the social and professional dimension of trust. Their article examines the extent to which recordkeepers are trusted (i.e. believed to have the necessary expertise) to manage and preserve digital records by ICT professionals, a key occupational group for potential collaboration and partnership. Duranti and Rogers' article develops a similar point by demonstrating that if records professionals are to continue to have the status of "trusted custodians" in a digital age, then they must acquire new competencies and their education programmes must identify new areas of required knowledge and the partnerships and external specialisations, for instance digital forensics, which will deliver them. Continuing with the theme of educating recordkeeping, professionals for effectively working in digital environments Bastian, Anderson, Harvey, Plum and Samuelsson describe the collaborative project between Simmons College (US) and Mid Sweden University to build and employ in their teaching virtual archives and preservation curriculum laboratories. The social dimension of professional development is also the theme of Hoy's article. She investigates issues of trust and professional identity by exploring the significance and influence of mentors and other senior colleagues on the attitudes and career trajectories of emerging professionals across a range of collecting institutions including archives, libraries and museums.

Other articles in this issue explore questions of what it means for archives and records to be trusted. The arguments advanced by Sundqvist inhabit a similar terrain to that covered by Moss, in that she is interested in exploring the relationships between digital records, recordkeeping systems and recordkeepers, trust and accountability. She concludes that there may be a paradox at work here, whereby professional and corporate actions to ensure trustworthiness may actually reveal a more general public decline of trust. Akmon, Zimmerman, Daniels and Hedstrom look at scientific, laboratory research data and stress the importance of managing the data in such a way that it can be trusted and re-used for future research. The article examines the challenges of managing the data to achieve this and suggests the potential for archival principles and expertise in contributing to the curation of trusted data. While significant international intellectual effort and resources have been directed to establishing the "trustworthiness" of institutional digital repositories, Paul Conway argues that less concern has been expressed over quality and usefulness of much of the digitised content maintained in these repositories. His article outlines a research project designed to develop measures of quality for digital content managed in a digital preservation context. 
The significance of archival materials in individual and collective dimensions, and hence the necessary responsibility to perform archival duties in a pluralistic and ethical manner, is apparent from discussions about identity and professional trust. Little's article examines the potential impact of the archive and archival research on an individual's sense of self and personal identity, but also argues that such explorations of self can take on a performative and public aspect through which the individual may be connected with collective identities. The contribution by McKemmish, Faulkhead and Russell, and based upon the Trust and Technology research project as well as their own individual research, examines the role of archives and archivists in the construction of Australian Indigeneity in the past and the present and outlines the possibilities for future re-imagined and trusted post-colonial archives and more ethical professional practice as a result of embracing both Indigenous frameworks of knowledge, memory and evidence, and digital technologies.

O'Neill (2002) argues that, perhaps somewhat paradoxically, the overwhelmingly availability of information and the rhetoric of transparency may not ultimately lead to greater public trust and in fact may contribute if not to a complete absence of trust then to an ever-growing culture of suspicion and distrust. One response of record creators to a sensationalist media and an open flow of information may be to seek to ensure that the records created and the recordkeeping systems that capture those records reveal nothing of consequence. However, another response might be for recordkeepers and others responsible for the management and dissemination of information to contribute to a cultural shift in governance and corporate behaviour, enabled by transparency and openness and documented by records that are trusted(-enough) to be an accurate, comprehensive and believable account of what happened and what was done. Transparency, openness and access to information on their own will not ensure an absence of deceit and corruption. However, along with a genuine desire in the media and elsewhere to support critical inquiry and a system pledged and able to hold those guilty of misdemeanours to account, then a recordkeeping profession committed to an ethical code of behaviour and inspired by a sense of social justice ensuring that the records they maintain are the best they can be, might contribute to replacing a culture of suspicion with one of trust. Amidst the mass of information and information providers available to us all, actively playing such a role should help maintain, reestablish or even establish for the first time the profession's reputation as trusted custodians looking after trustworthy(-enough) records.

Finally, as guest editors of this special issue, we would like to thank the other members of FARMER and NAET who helped organise the Oxford conference, Louise Gordon of Wolfson College for helping us run such a successful event, and all the production staff at Springer and the editors of Archival Science for all their support and help in putting this issue together.

\section{Reference}

O’Neill O (2002) Questions of trust. BBC Reith lecture series. http://www.bbc.co.uk/podcasts/series/ rla76/all. Accessed 16 September 2011 


\section{Author Biographies}

Andrew Flinn is a Senior Lecturer and Director of the Archives and Records Management and Records and Archive Management (International) MA programmes in the Department of Information Studies at University College London and was the chair of the UK and Ireland Forum for Archives and Records Management Education and Research (FARMER) between 2008 and 2011. In 2011, he was a visiting professor and the Allan Smith Visiting Scholar in the Graduate School of Library and Information Science at Simmons College, Boston. He has recently completed a UK Arts and Humanities Research Council funded research project "Community archives and identities" that examined the motivations, impacts and challenges of independent and community-led archive and heritage initiatives of African, Asian and other heritage groups in the UK and also worked on another AHRC funded project to assess the impact of Freedom of Information legislation on local government recordkeeping. His most recent writings include "The impact of independent and community archives on professional archival thinking and practice" in Hill (ed) The Future of Archives and Recordkeeping (London, 2011), and "Archival Activism: Independent and Community-led Archives, Radical Public History and the Heritage Professions", InterActions: UCLA Journal of Education and Information Studies, 7(2) (2011).

Elizabeth Shepherd is Professor of Archives and Records Management at University College London, Department of Information Studies (DIS). She established a research centre, ICARUS, to bring together researchers in records and archives management. Elizabeth's research interests include the relationships between records management and information policy compliance and the development of the archive profession in England. She serves on the editorial boards of Archival Science, Journal of the Society of Archivists and the Records Management Journal. She has published numerous articles, (with Geoffrey Yeo) the internationally best selling book Managing Records: a handbook of principles and practice (Facet Publishing, 2003) and the monograph Archives and Archivists in 20th Century England (Aldershot, Hants.: Ashgate, 2009). 